\title{
Servikal posterior longitudinal bağ ossifikasyonunun posterior yaklaşım ile cerrahi tedavisi
}

\section{Surgical treatment of the ossification of cervical posterior longitudinal ligament by dorsal approach}

\author{
Cem Sever, Meriç Enercan
}

İstanbul Skolyoz ve Omurga Cerrahisi Merkezi, İstanbul Florence Nightingale Hastanesi, İstanbul

\begin{abstract}
Posterior longitudinal bağ (ligament) ossifikasyonu (PLLO), progresyon sürecinde spinal kordun ventral ve ventrolateral olarak basıya maruz kalmasına ve ilerleyici servikal miyelopatiye neden olur. Posterior yaklaşım anterior yaklaşıma göre teknik olarak daha kolay bir yöntemdir; PLLO hastalarında sık görülen multi-segmental lezyonlar için daha uygun olması ve iyatrojenik nörolojik hasar, dura yırtığı ve semptomatik beyin omurilik sıvısı (BOS) kaçağı gelişmesi gibi komplikasyonların daha az sıklıkta görülmesi, önemli avantajlarıdır. Posterior yaklaşım ile cerrahi tedavi seçenekleri arasında, "tek başına laminektomi", "laminektomi ile birlikte füzyon" ve "laminoplasti" yer alır. Cerrahi öncesi servikal kifozun varlığı, ileri derecede dar kanal, travma öyküsü veya semptomların çok uzun süreden beri var olması gibi faktörler bu yaklaşımdan elde edilecek başarı oranını düşürse de, PLLO'nun posterior yaklaşım ile tedavisinde, birçok hastada düşük komplikasyon oranlarıyla başarılı sonuçlar elde edilmektedir. Cerrahi öncesi belirgin servikal kifozu olan miyelopatik hastalarda, kombine anterior posterior yaklaşım, posterior yaklaşıma tercih edilmelidir.
\end{abstract}

Anahtar sözcükler: posterior longitudinal bağ kalsifikasyonu; laminektomi; laminoplasti; posterior yaklaşım
Ossification of the posterior longitudinal ligament (OPLL), while progressing, compresses the ventral or ventrolateral aspects of the spinal cord causing progressive cervical myelopathy. Dorsal approach is technically less demanding when compared to anterior approach; it is less frequently associated with serious complications such as intraoperative neural injury, symptomatic cerebrospinal fluid leakage, adjacent segment disease, and is more applicable to multisegmental lesions, as it is often the case with OPLL patients. Dorsal procedures include laminectomy alone, laminectomy with fusion, and laminoplasty. Dorsal surgery for OPLL yields satisfactory results in the majority of patients although presence of preoperative cervical kyphosis, severe canal compromise, a history of trauma, or a long duration of symptoms failed to obtain optimal surgical results. For patients with significant preoperative cervical kyphosis and myelopathy, combined anterior posterior surgery should be preferred rather than posterior approach.

Key words: ossification of posterior longitudinal ligament; laminectomy; laminoplasty; posterior approach

problem olup, erkeklerde kadınlara oranla iki kat daha sık görülmektedir. ${ }^{[1,2]}$ Genelde hayatın 5. ve 6. dekadında semptom vermeye başlayan bu sorun, yaygın idiyopatik iskelet hiperosteozu (DiSH hastalığı), ankilozan spondilit ve diğer spondilo-artropatilerle ilişkili olabilir. Patogenezi tam olarak bilinmemekle beraber; kollajen $\mathrm{A} 2$ geni (COL11A2), transforming growth factor - beta 1 (TGF- $\beta 1$ ), insülin benzeri büyüme faktörü ve interlökin-7'nin PLLO gelişiminde etkili olduğu bildirilmiştir. ${ }^{[3,4]}$

- İletişim adresi: Doç. Dr. Meriç Enercan, İstanbul Omurga Merkezi, İstanbul Florence Nightingale Hastanesi. Abide-i Hürriyet Cad. No: 166, Şişli, İstanbul Tel: 0212 - 3756565 e-posta: enercan@yahoo.com

- Geliș tarihi: 5 Nisan $2017 \quad$ Kabul tarihi: 5 Nisan 2017 


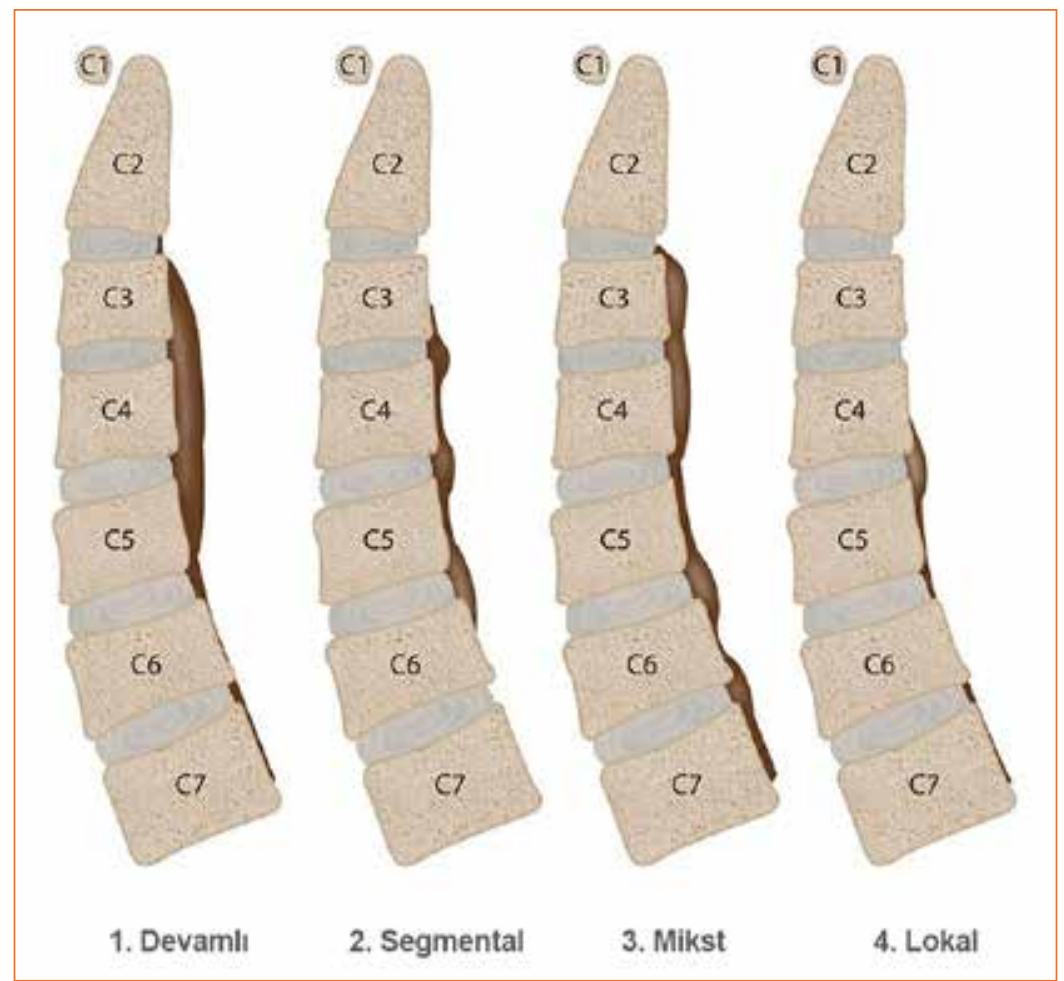

Şekil 1. Hirabayashi tarafindan 1) devamlı, 2) segmental, 3) mikst ve 4) lokalize olmak üzere dört farklı tipte sınıflandırılmıştır.

Servikal PLLO, Hirabayashi tarafindan, 1) devaml, 2) segmental, 3) mikst ve 4) lokalize olmak üzere dört farklı tipte sınıflandırılmıştır (Şekil 1). ${ }^{[5]}$

Erken evrelerde ve olguların çoğunda hastalık yavaş ve asemptomatik seyrederken, \%30'luk bir kısmında minör bir travma sonrası ciddi kuvvet kaybının eşlik ettiği, nörolojik fonksiyonlarda ani olarak başlayan bozulma şeklinde ortaya çıkabilir. Semptomatik PLLO olan hastalarda; zaman içinde ellerde uyuşma, elin ince becerilerinde bozulma, yürüme güçlüğü, denge bozukluğu, hiperrefleksi, idrar ve gaita kontrol bozukluğu gibi bulgular ve miyelopatik semptomlar ortaya çıkar. Miyelopatik semptomlar ortaya çıktığında, konservatif tedavi ile düzelme beklenmez ve bu olgularda miyelopatinin derecesi, etkilenen segment sayısı, primer patolojinin yerleşim yeri, servikal sagittal dizilimin durumu ve cerrahın tecrübesine göre, anterior, posterior veya kombine yaklaşımlardan uygun olanı seçilerek cerrahi tedavi uygulanır.

PLLO'nun posterior yaklaşım ile cerrahi tedavi seçenekleri arasında; "tek başına laminektomi”, "laminektomi ile birlikte füzyon" ve "laminoplasti" yer alır. Posterior yaklaşım anterior yaklaşımla karşılaştırıldığında; teknik olarak daha kolay bir prosedür olması, multisegmental lezyonlar için daha uygun olması ve iyatrojenik nörolojik hasar, dura yırtığı ve semptomatik beyin omurilik sıvısı (BOS) kaçağı gelişmesi gibi komplikasyonlar daha az sıklıkta görülmesi, önemli avantajlarıdır. PLLO'da patoloji spinal kordun ventral yüzünde yerleşmiş olmasına rağmen, posteriorden dekompresyonla spinal kord dorsale doğru yer değiştirir ve ön yüzündeki bası indirekt olarak kalkar. Posterior cerrahi göreceli olarak daha güvenlidir ve anterior yaklaşımın neden olabileceği vokal kord paralizisi, karotis damar hasarı, özofagus yaralanması gibi ciddi morbiditeye neden olan sorunlar görülmez. ${ }^{[5-10]}$

\section{TEK BAŞINA LAMINEKTOMI}

Posterior cerrahi yaklaşımlardan olan tek başına laminektomi tekniği, diğer seçeneklere göre daha basit bir teknik olmasına rağmen çok daha az sıklıkta tercih edilmektedir. Laminektomi ile birlikte, kanal çapı genişler, spinal kordun indirekt dekompresyonu sağlanarak nörolojik semptomlar belirgin olarak geriler. Tek başına laminektomi için en uygun adaylar; ileri yaşta, servikal instabilitesi olmayan, servikal lordozu $10^{\circ}$ 'nin üzerinde ve PLLO kalınlığı $7 \mathrm{~mm}$ altında, multi-segmental tutulum gösteren ve sürekli tipte PLLO olan olgulardır. Laminektomi esnasında stabiliteyi korumak 

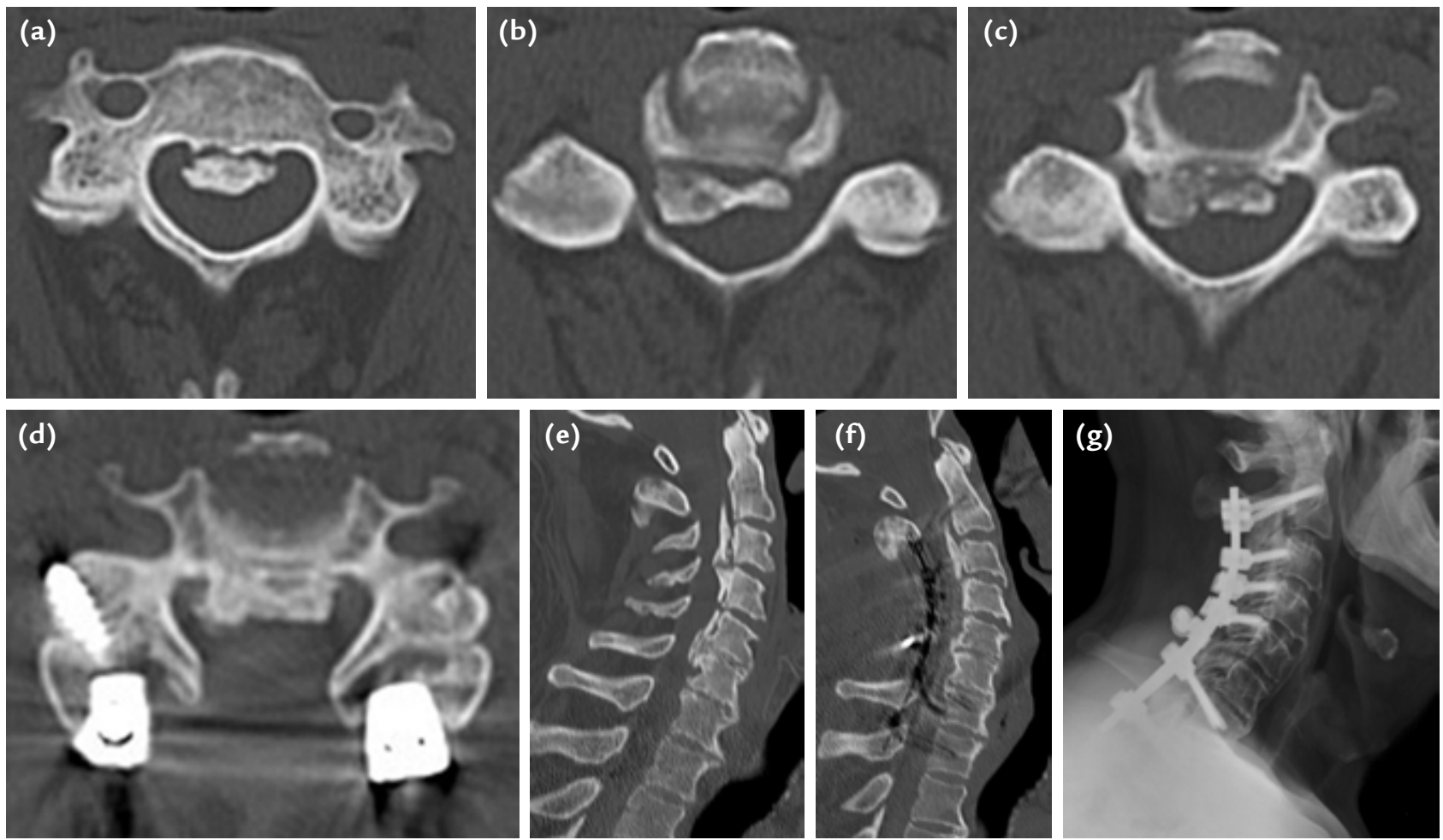

Şekil 2. a-g. İleri düzeyde kanal daralmasına neden olan PLLO. Preoperatif bilgisayarlı tomografi aksiyel (a-d), sagittal (e) kesitleri. Posterior enstrümentasyon ve laminektomi ile yeterli dekompresyon elde edilir (f, $\mathbf{g})$.

için, faset eklemin mediyalinin \%25'inin alınması ve lateral \%75'lik kısmının korunması önerilmiştir. Yapılan biyomekanik çalışmalarda, faset eklemin \%50'sinden fazla yapılan rezeksiyonların ciddi instabilite oluşturduğu gösterilmiştir. ${ }^{[11]}$ Laminektomi sonrası gelişen instabilite ve ortaya çıkan ilerleyici kifotik deformite, tek başına laminektominin tercih edilmesini sınırlayan en önemli faktördür. Kato ve arkadaşlar ${ }^{[12]}$, ortalama 14 yıl takip süreli çalışmalarında, hastaların \%47'sinde progresif kifotik deformite geliştiğini, ancak bunun herhangi bir nörolojik gerilemeye neden olmadığını bildirmişlerdir. Lee ve arkadaşlar ise, ortalama beş yıllık takip sonunda dört seviye ve üzeri laminektomi uyguladıkları hastaların sadece \%24'ünde kifotik deformite geliştiğini ve PLLO'nun kendisinin stabiliteye katkısı olduğunu bildirmişlerdir. ${ }^{[13]}$

Ayrıca, diğer tekniklerle karşılaştırıldığında, tek başına laminektomi uygulandıktan sonra PLLO'nun progresyona devam etme olasılığı daha yüksektir. ${ }^{[14]}$

\section{LAMINEKTOMI VE FÜZYON}

Laminektomi ve füzyon tekniği, enstrümantasyon ile birlikte uygulanan laminektomiyi içerir ve genel olarak servikal miyelopatinin tedavisinde en sık tercih edilen yöntemdir. Tek başına laminektomi ile karşılaştırıldığında, cerrahi sonrası geçilebilecek instabilite ve kifotik deformiteyi engelleyerek sagittal dizilimi korur; enstrümantasyonun sağladığı ek stabilite sayesinde daha geniş dekompresyon uygulanmasına olanak sağlar. Laminektomi ve füzyonun, aksiyel boyun ağrısının azalmasında diğer tekniklere göre daha etkili olduğu bildirilmiştir. ${ }^{[15]}$ Subaksiyel servikal omurgada lateral mass vidaları ile tespit güvenli ve güçlü stabilite sağlarken, $C 2$ ve $C 7$ seviyelerinde sıklıkla pedikül vida fiksasyonu tercih edilmektedir. Enstrümantasyonun prosedüre eklenmesi; sinir kökü ve vertebral arter hasarını, lateral mass kırı̆̆ı, implant yetersizliği, psödoartroz ve komşu segment problemleri gibi komplikasyonların oranını belirli oranda arttırmaktadır. ${ }^{[1,2]}$

Laminektomi ve füzyon tekniği; servikal lordozun korunduğu ya da kifotik deformitenin esnek ve düzelebilir olduğu, segmental instabilite varlığında, multi-segmental (üç seviyeden fazla) tutulum gösteren, patolojinin servikotorasik bileşkeye uzandığı ileri yaşta olgular için idealdir (Şekil 2). ${ }^{11,2]}$

Laminektomi ve füzyon sonrası görülen önemli ve sık komplikasyonlarda biri de C5 sinirinin geçici parezisidir. Patofizyolojisi tam olarak açıklanamasa da, 

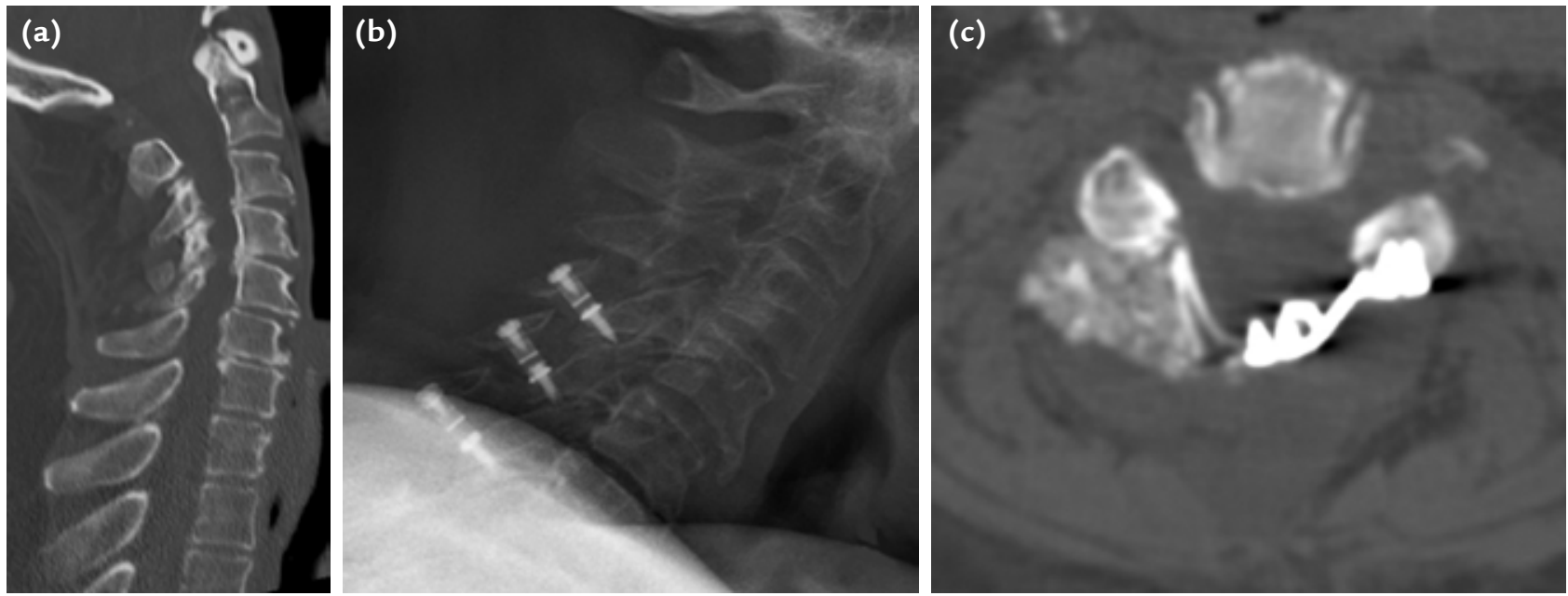

Şekil 3. a-c. Laminoplasti yapılan sahanın tekrar kapanmaması ve kanalı daraltmaması için laminoplasti plağı kullanılabilir.

servikal lordozun artması ve laminektomi sonrası spinal kordun posteriora doğru yer değiştirmesi ile birlikte, anatomik olarak daha kısa olan C5 sinir köklerinin gerilmesi sonucu geliştiği ileri sürülmüştür. $\mathrm{Bu}$ durumun, spinal kordun reperfüzyon yaralanmasına sekonder geliştiği de öne sürülmüştür. Özellikle laminoplasti tekniği ile karşılaştırıldığında; geçici C5 sinir parezisinin, laminektomi ve füzyon sonrası daha sık ve kuvvet kaybı açısından daha belirgin geliş̧tiği bildirilmiştir. ${ }^{[16]}$

\section{LAMINOPLASTI}

Post-laminektomi kifozunu ve post-laminektomi yapışıklıklarına bağlı gelişen bası problemleri engellemek için, alternatif olarak laminoplasti tekniği geliştirilmiştir. 1980'li yılların başında, Hirabayashi tarafından popülarize edilen laminoplasti tekniği, günümüze kadar pek çok modifikasyon geçirmiştir. Günümüzde, allogreft kullanımına olanak sağlayan ve laminoplasti hattının tekrar kapanmasını önleyen implantlar, bu tekniğin etkinliğini arttırmaktadır. Titanyum yerine paslanmaz çelik tasarımlar, cerrahi sonrası takip döneminde manyetik rezonans (MR) görüntüleme kalitesini arttırmıştır. ${ }^{[1,2]}$

Laminoplasti; servikal lordozun korunduğu (minimum $10^{\circ}$ ), PLLO kalınlığının 7 mm'den daha az olduğu, kanal çapının \%50'sinden daha az darlığa neden olan, multisegment tutulum gösteren 60 yaşından genç miyelopatik hastalar için uygun bir tekniktir. Tanımlanmış birçok laminoplasti tekniği olmasına rağmen, açık kapı (open-door) ve çift kapı (double-door) laminoplasti teknikleri daha sık tercih edilmektedir (Şekil 3).

\section{CERRAHI TEKNIK}

Hasta genel olarak yüzükoyun, çivili başıkta ya da ay başlıkta yatar pozisyonda hazırlanır. Cerrahi ekspojur esnasında, özellikle erektör spina kaslarının C2'ye yapışma yeri ile cerrahi sonrası aksiyel semptomların gelişmesini önlemek için C7 spinöz çıkıntısına yapışan nuchal ligament'in yapışma yeri korunmalıdır. Yüksek devirli turr kullanılarak, bir tarafta lamina ile faset eklemlerin birleşme noktalarına yakın bir oluk açılır. Daha sonra dikkatli bir şekilde, laminada açılan bu oluk üzerinden epidural alana kadar kesilir. Hangi tarafa açık kapı tekniği uygulanacağına, PLLO'nun baskın olduğu tarafa ve klinik semptomlara göre karar verilmelidir. Daha sonra, karşı tarafta menteşe görevi görecek oluk, laminanın açılmasına olanak sağlayacak şekilde, biraz daha lateralde ve daha geniş olarak açılmalıdır. Laminanın sadece dış korteksinde kesim yapılır ve iç korteksin korunmasına özen gösterilmelidir. Aksi takdirde bu, "yüzen lamina" oluşmasına neden olur. Laminanın kaudalden kraniyale doğru kaldırılması önerilir. Flaval bağ ve epidural yapışıklıklar gevşetilmelidir. Hirabayashi'nin tanımladığı klasik teknikte; multifidus kasının faset eklemlere yapışma noktalarına tespit sütürleri veya lateral mass üzerine çapa sütürler yerleştirilir, dikiş materyalleri her bir spinöz çıkıntıyı dolanacak şekilde geçirilir ve gergin şekilde sıkıca bağlanır. Günümüzde, kaldırılan lamina tekrar kapanmaması için, allogreft bloklar ve özel tasarımlı mini-plaklar vidalarla tespit edilmektedir. Çift kapı laminoplasti yönteminde ise, spinöz çıkıntılar ortadan kesilerek yanlara doğru açılır ve spinal kanal genişletilir. Spinöz çıkıntılarının ayrık kalması için kemik grefti ve özel plak sistemleri kullanılır. ${ }^{[2]}$ Hirabayashi, yaptığı 


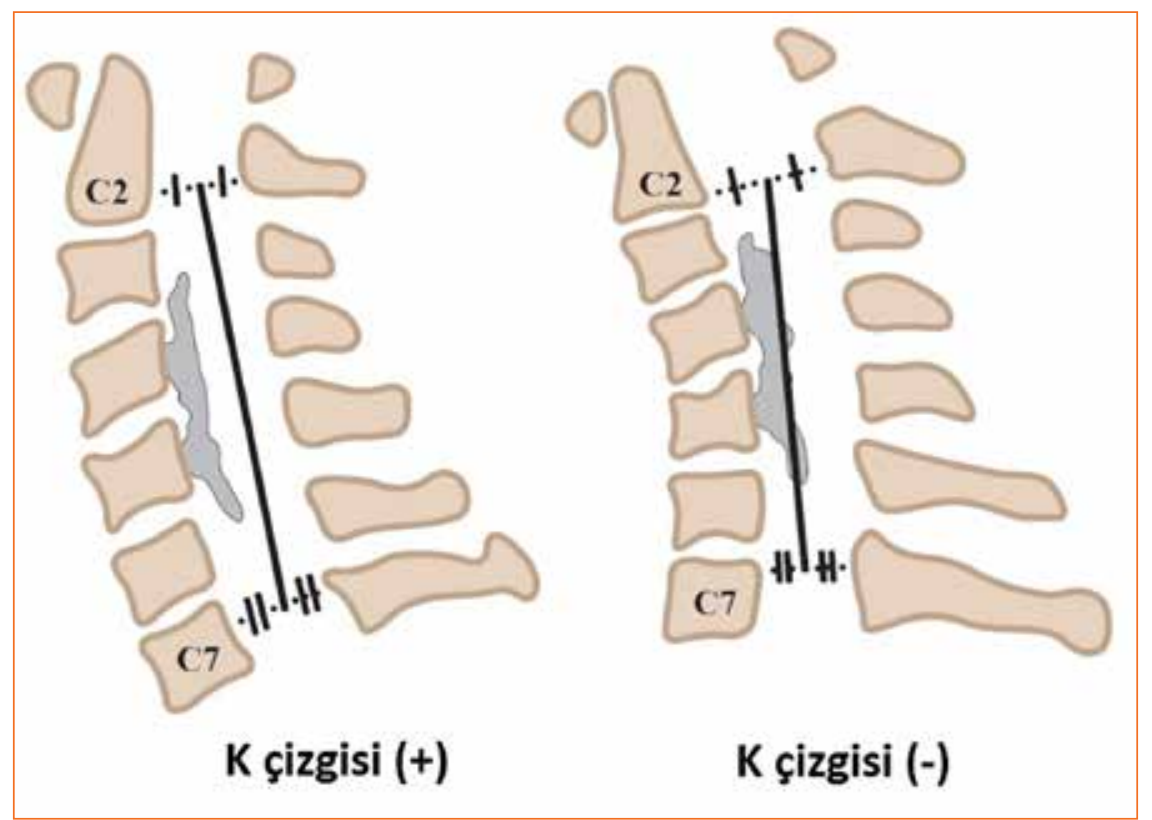

Şekil 4. K-çizgisi; $C 2$ ve $C 7$ seviyelerinde spinal kanalın orta noktalarını birleştiren düz bir çizgidir. PLLO'nun K çizgisini geçmediği durum “K-çizgisi pozitif”, geçtiği durum ise "K-çizgisi negatif" olarak tanımlanır.

karşılaştırmalı çalışmada; açık kapı laminoplasti ile kanalda daha geniş bir açılma sağlandığını, çift kapı laminoplasti ile laminaların inklinasyon açılarının belirgin olarak arttığını ortaya koymuştur. ${ }^{[17]}$

Laminoplastinin uzun dönem takip sonuçları incelendiğinde, \%47-63 oranlarında iyileşme bildirilmiştir. ${ }^{[18]}$ Ratliff ve Cooper, laminoplasti sonrası Japon Ortopedi Birliği (JOA) skorlarına göre yaptığı fonksiyonel değerlendirmede, erken dönemde $\% 54$ ve beş yıllık takip sonunda ortalama \%48 iyileşme bildirmişlerdir. ${ }^{[19]}$ Matz ve arkadaşları da benzer şekilde, JOA skorlarında \%5560 oranlarında artma tespit etmişlerdir. ${ }^{[20]}$ Chiba ve arkadaşları, açık kapı laminoplasti yaptıkları ve 14 yıl takip ettikleri 53 hastada, beş yıl sonrasında ortalama JOA skorlarında kademeli olarak düşüş tespit etseler de, ortalama nihai düzelme oranını $\% 47,9$ olarak, beş yıl ve sonrasında, geç dönemde $\% 30$ hastanın nörolojik semptomlarında bozulma bildirmişlerdir. ${ }^{[7]}$ Ogawa, PLLO nedeniyle laminoplasti yapılan hastalarda beş yıl sonrasında da tatminkar sonuç aldıklarını bildirmişler ve semptomların ortaya çıkışı ile cerrahi arasındaki geçen sürenin, uzun dönem sonuçları etkileyen en önemli faktör olduğunu ortaya koymuşlardır. ${ }^{[21]}$

Ratliff ve Cooper çalışmalarında, laminoplasti sonrası \%10 oranında postlaminoplasti kifozu, \%35 oranında servikal dizilimde bozulma, servikal hareket açıklığında \%50 oranında azalma bildirmişlerdir. ${ }^{[19]}$ Posterior servikal yaklaşıma bağlı aksiyel boyun ağrısı, \%6-60 oranlarında görülebilen diğer bir sorundur.
Laminoplasti sonrası geçici C5 sinir parezisi \%4,6-16,3 oranlarında; laminektomi ile karşılaştırıldığında daha az sıklıkta ve daha hafif şiddette görülmektedir. ${ }^{[16]}$

Genel olarak, PLLO için laminoplasti sonuçları kabul edilebilir düzeydedir. Ancak, kötü sonuca yol açabilecek birçok farklı neden bildirilmiştir. Bunlar; cerrahi öncesi servikal kifoz varlığı, spinal kanalı \%60'dan fazla daraltan ossifikasyonun olması, cerrahinin yapıldığı zamanki hastanın yaşı, servikal travma öyküsünün olması, T2 ağırlıklı MR görüntülemede belirgin intramedüller sinyal artışı/yoğunluğu, semptomların ortaya çıkışı ile cerrahi arasında geçen sürenin uzunluğu, ve segmental tipte PLLO'nun olmasıdır. ${ }^{[7-9,18,22-26]}$ Mauro ve arkadaşları da, dinamik faktörleri inceledikleri çalışmalarında, cerrahi öncesi C2-C7 hareket açıklığının $20^{\circ}$ 'den fazla olduğu hastalarda cerrahi sonrası dönemde daha kötü klinik sonuçlar saptamışlar ve cerrahi öncesi hipermobil servikal omurgası olan hastalarda füzyon yapılmasını önermişlerdir. ${ }^{[27]}$ Kim ve arkadaşları da, cerrahi öncesinde daha yüksek T1 eğim açısına sahip olan hastalarda laminoplasti sonrası daha fazla lordoz kaybı tespit etmişlerdir. ${ }^{[28]}$

PLLO'nun cerrahi tedavisinde hangi tekniğin seçilmesi gerektiğine karar vermek güçtür. Fujiyoshi ve arkadaşları, PLLO'da cerrahi tedaviye karar vermede, "K-çizgisi" olarak isimlendirdikleri bir indeks tanımlamışlardır. K-çizgisi; C2 ve C7 seviyelerinde spinal kanalın orta noktalarını birleştiren düz bir çizgidir (Şekil 4). K-çizgisini kullanarak; servikal vertebraların 
kifotik dizilimini ve PLLO'nun spinal kanalı ne kadarını işgal ettiğini değerlendirmişlerdir. PLLO'nun K çizgisini geçmediği "K-çizgisi pozitif" hastaların laminoplastiye uygun oldukları, "K-çizgisi negatif" olan hastalarda ise posterior dekompresyonla spinal kordun dorsale doğru yer değiştirmesinin ve nörolojik semptomlarda düzelmenin yeterli olmadığını ortaya koymuşlardır.[23] Lee ve arkadaşları, her üç tekniğin klinik sonuçlarını karşılaştırdıkları ve sagittal dizilim ile ilişkilerini inceledikleri çalışmaları sonucunda, PLLO'nun cerrahi tedavisi için algoritma önermişlerdir. Bu algoritmaya göre, üç ve daha fazla seviyeyi ilgilendiren PLLO'nun miyelopatiye neden olduğu hastalarda; servikal sagittal dizilim lordotik/nötral ve global sagittal balans normal ise (C2-C7 SVA <40 $\mathrm{mm}$ ), laminoplasti tekniğini önermişlerdir. Esnek ve düzelebilen kifoza sahip ya da global sagittal balansı bozuk olan hastalarda laminektomi ve füzyon tekniğini; rijid ve bariz kifotik hastalar için ise anterior cerrahi önermişlerdir. ${ }^{[14]}$

\section{SONUÇ}

PLLO'nun neden olduğu miyelopatinin cerrahi tedavisinde, posterior yaklaşım ile başarılı sonuçlar elde edilebilmektedir. Posterior yaklaşımlardan hangisinin seçileceği; hastanın yaşı, servikal omurganın sagittal dizilimi ve mobilitesi, miyelopatinin derecesi, etkilenen segment sayısı, PLLO tipi, ve cerrahın tecrübesi gibi faktörlere bağlıdır.

\section{KAYNAKLAR}

1. Matsumato M, Toyama $Y$, Chiba K. Surgery for Ossification of the Posterior Longitidunal Ligament: Dorsal Approach. In: Benzel EC, editor. The Cervical Spine, 5th ed. Philadelphia: Lippincott Williams \& Wilkins; 2012. p.1044-54.

2. Ray WZ, Farrokhi F, Dailey A. Ossification of the Posterior Longitudinal Ligament. In: Kim D, Vaccaro A, Dickman C, Cho D, Lee S, Kim I, editors. Surgical Anatomy \& Techniques to the Spine, 2nd ed. Philadelphia: Elsevier Saunders; 2013. p.232-41.

3. Koga H, Sakou T, Taketomi E, Hayashi K, Numasawa T, Harata S, Yone K, Matsunaga S, Otterud B, Inoue I, Leppert M. Genetic mapping of ossification of the posterior longitudinal ligament of the spine. Am J Hum Genet 1998;62(6):1460-7. Crossref

4. Song J, Mizuno J, Hashizume $\mathrm{Y}$, Nakagawa $\mathrm{H}$. Immunohistochemistry of symptomatic hypertrophy of the posterior longitudinal ligament with special reference to ligamentous ossification. Spinal Cord 2006;44(9):576-81. Crossref

5. Hirabayashi K, Miyakawa J, Satomi K, Maruyama T, Wakano K. Operative results and postoperative progression of ossification among patients with ossification of cervical posterior longitudinal ligament. Spine (Phila Pa 1976) 1981;6(4):354-64.

6. Hirabayashi K, Toyama $\mathrm{Y}$, Chiba K. Expansive laminoplasty for myelopathy in ossification of the longitudinal ligament. Clin Orthop Relat Res 1999;(359):35-48.
7. Chiba K, Ogawa $\mathrm{Y}$, Ishii K, Takaishi $\mathrm{H}$, Nakamura $\mathrm{M}$, Maruiwa $\mathrm{H}$, Matsumoto $M$, Toyama $Y$. Long term results of expansive open-door laminoplasty for cervical myelopathyaverage 14-year follow-up study. Spine (Phila Pa 1976) 2006;31(26):2998-3005. Crossref

8. Chiba K, Oqawa Y, Matsumoto M, et al. Expansive open-door laminoplasty for ossification of the posterior longitudinal ligament of the cervical spine: surgical indications, technique, and outcomes. In: Yonenobu K, Nakamura K, Toyama Y, editors. OPLL, ossification of the posterior longitudinal ligament, 2nd ed. Tokyo: Springer; 2006. p.193-9.

9. Satomi K, Hirabayashi K. Ossification of the posterior longitudinal ligament. In: Herkowitz HN, Garfin SR, Balderston RA, Eismont FJ, Bell GR, editors. RothmanSimeone: The Spine, 4th ed. Philadelphia: W. B. Saunders; 1999. p.565-80.

10. Seichi A, Takeshita K, Ohishi I, Kawaguchi H, Akune T, Anamizu Y, Kitagawa T, Nakamura K. Long-term results of double-door laminoplasty for cervical stenotic myelopathy. Spine (Phila Pa 1976) 2001;26(5):479-87.

11. Epstein NE. Cervical Myelopathy: Laminectomy. In: Benzel EC, editor. The Cervical Spine, 5th ed. Philadelphia: Lippincott Williams \& Wilkins; 2012. p.970-9.

12. Kato $\mathrm{Y}$, Iwasaki M, Fuji T, Yonenobu K, Ochi T. Long-term follw-up results of laminectomy for cervical myelopathy caused by ossification of the posterior longitudinal ligament. J Neurosurg 1998;89(2):217-23. Crossref

13. Lee SE, Chung CK, Jahng TA, Kim HJ. Long-term outcome of laminectomy for cervical ossification of the posterior longitudinal ligament. J Neurosurg Spine 2013;18(5):46571. Crossref

14. Lee $\mathrm{CH}$, Jahng TA, Hyun SJ, Kim KJ, Kim HJ. Expansive Laminoplasty Versus Laminectomy Alone Versus Laminectomy and Fusion for Cervical Ossification of the Posterior Longitudinal Ligament: Is There a Difference in the Clinical Outcome and Sagittal Alignment? Clin Spine Surg 2016;29(1):E9-15. Crossref

15. Highsmith JM, Dhall SS, Haid RWJr, Rodts GEJr, Mummaneni PV. Treatment of cervical stenotic myelopathy: a cost and outcome comparison of laminoplasty versus laminectomy and lateral mass fusion. J Neurosurg Spine 2011;14(5):61925. Crossref

16. Lee SH, Suk KS, Kang KC, Cho SW, Juh HS, Lee JH, Kim KT. Outcomes and Related Factors of C5 Palsy Following Cervical Laminectomy with Instrumented Fusion Compared with Laminoplasty. Spine (Phila Pa 1976) 2016;41(10):E574-9. Crossref

17. Hirabayashi S, Yamada $H$, Motosuneya $T$, Watanabe $Y$, Miura $\mathrm{M}$, Sakai $\mathrm{H}$, Matsushita T. Comparison of enlargement of the spinal canal after cervical laminoplasty: open-door type and double-door type. Eur Spine J 2010;19(10):1690-4. Crossref

18. Choi BW, Song KJ, Chang H. Ossification of the posterior longitudinal ligament: a review of literature. Asian Spine J 2011;5(4):267-76. Crossref

19. RatliffJK, Cooper PR. Cervical laminoplasty: a critical review. J Neurosurg 2003;98(3 Suppl):230-8.

20. Matz PG, Anderson PA, Groff MW, Heary RF, Holly LT, Kaiser MG, Mummaneni PV, Ryken TC, Choudhri TF, Vresilovic EJ, Resnick DK; Joint Section on Disorders of the Spine and Peripheral Nerves of the American Association of Neurological Surgeons and Congress of Neurological Surgeons. Cervical laminoplasty for the treatment of cervical degenerative myelopathy. J Neurosurg Spine 2009;11(2):157-69. Crossref 
21. Ogawa $Y$, Toyama $Y$, Chiba $K$, Matsumoto $M$, Nakamura $M$, Takaishi $\mathrm{H}$, Hirabayashi $\mathrm{H}$, Hirabayashi K. Long-term results after expansive open-door laminoplasty for ossification of the posterior longitudinal ligament of the cervical spine. J Neurosurg Spine 2004;1(2):168-74. Crossref

22. Suda K, Abumi K, Ito M, Shono Y, Kaneda K, Fujiya M. Local kyphosis reduces surgical outcomes of expansive open-door laminoplasty for cervical spondylotic myelopathy. Spine (Phila Pa 1976) 2003;28(12):1258-62. Crossref

23. Fujiyoshi T, Masashi Yamazaki M, Kawabe J, Endo T, Furuya T, Koda M, Okawa A, Takahashi K, Konishi H. A new concept for making decisions regarding the surgical approach for cervical ossification of the posterior longitudinal ligament. The K-line. Spine (Phila Pa 1976) 2008;33(26):E990-3. Crossref

24. Iwasaki M, Okuda S, Miyauchi A, Sakaura H, Mukai Y, Yonenobu K, Yoshikawa $\mathrm{H}$. Surgical strategy for cervical myelopathy due to ossification of the posterior longitudinal ligament: Part 1: Clinical results and limitations of laminoplasty. Spine (Phila Pa 1976) 2007;32(6):647-53. Crossref
25. Ogawa $Y$, Chiba $K$, Matsumoto $M$, Nakamura $M$, Takaishi $\mathrm{H}$, Hirabayashi $\mathrm{H}$, Hirabayashi K, Nishiwaki $\mathrm{Y}$, Toyama $\mathrm{Y}$. Long-term results after expansive open-door laminoplasty for the segmental-type of ossification of the posterior longitudinal ligament of the cervical spine: a comparison with nonsegmental-type lesions. J Neurosurg Spine 2005;3(3):198-204. Crossref

26. Masaki Y, Yamazaki M, Okawa $A$, et al. An analysis of factors causing poor surgical outcome in patients with cervical myelopathy due to ossification of the posterior longitudinal ligament: anterior decompression with spinal fussion versus laminoplasty. J Spinal Disord Tech 2007;20(1):7-13. Crossref

27. Maruo K, Moriyama T, Tachibana T, Inoue S, Arizumi F, Daimon T, Yoshiya S. The impact of dynamic factors on surgical outcomes after double-door laminoplasty for ossification of the posterior longitudinal ligament of the cervical spine. J Neurosurg Spine 2014;21(6):938-43. Crossref

28. Kim B, Yoon do H, Ha Y, Yi S, Shin DA, Lee CK, Lee N, Kim $\mathrm{KN}$. Relationship between T1 slope and loss of lordosis after laminoplasty in patients with cervical ossification of the posterior longitudinal ligament. Spine J 2016;16(2):219-25. Crossref 